\title{
PAULA ALMOZARA
}

\section{「」}

Manual de localização imaginária:

paisagem, processo, técnica e ficção

RESUMO

O texto aborda as questões relativas à construção poética do conjunto de trabalhos intitulado Manual de localização imaginária, como resultado do projeto de pesquisa institucional “paisagem-percurso”. São apresentados os relatos sobre os processos resultantes de conexões híbridas entre linguagens, e utilização de elementos presentes em tecnologias de localização, a partir de propostas que estabelecem uma relação dialógica entre imaginação e realidade, na qual elementos ficcionais e documentais são utilizados para construir novas possibilidades de perceber e de se relacionar com a paisagem.

PALAVRAS-CHAVE

Paisagem. Processos. Técnica. Imaginação. Ficção. 


\section{MANUAL DE LOCALIZAÇÃO IMAGINÁRIA: PAISAGEM, PROCESSO,TÉCNICA E FICÇÃO}

Manual de localização imaginária é um conjunto de produção poética, estabelecido a partir de diversas séries de trabalhos, que apresentam conexões híbridas entre linguagens, como a gravura, o audiovisual, a fotografia, e a apropriação de elementos presentes em tecnologias de localização geográfica.

A ideia desse conjunto é propor uma reflexão "visual" sobre o modo fragmentado como nos relacionamos com o espaço e com a paisagem, e também a forma como os meios contemporâneos de deslocamento e localização determinam microficções, que instauram possíveis camadas de história e memória na construção da paisagem.

Em seu início, Manual de localização imaginária era um processo experimental com produções gráficas e audiovisuais, que se caracterizava pelo uso de referências geotecnológicas; ou seja, usava a visualidade presente em certos aparatos tecnológicos, como mapas, coordenadas de GPS etc., para criar lugares imaginários, partindo do pressuposto de que:

Para que exista uma paisagem não basta que exista "natureza"; é necessário um ponto de vista e um espectador; é necessário, também, um relato que dê sentido ao que se vê e experimenta;é consubstancial à paisagem, portanto, à separação entre homem e mundo. Não de trata de uma separação total, entretanto, mas de uma ambígua forma de relação, onde o que se olha se reconstrói a partir de recordações, perdas, nostalgias próprias e alheias, que remetem às vezes a larguíssimos períodos da sensibilidade humana, outras a modas efêmeras. $O$ olhar paisagístico é o olhar do exilado, daquele que conhece sua estranheza radical com as coisas, mas recorda ou, melhor, constrói um passado, uma memória, um sentido. (Aliata, 2008, p. 12)

A estratégia de ação artística dentro do Manual de localização imaginária combina, assim, fragmentos de experiências reais e ficcionais que, conectados, reinventam 
e reestruturam as possibilidades formais de representação de um lugar - espaço subjetivado.

Nesse processo de construção poética, há também um questionamento que recai sobre o poder dos sistemas de informação e localização - que exercem um fascínio pela forma instantânea como os dados são processados - e pelo acesso a essa tecnologia na integração do GPS aos dispositivos móveis, como celulares, tablets e câmeras.

De modo geral, em maior ou menor escala, os aparatos tecnológicos estão presentes na relação entre paisagem e deslocamento, fundamentando o modo como nos localizamos ou interagimos com um determinado espaço. Em diversos momentos da história, observa-se de maneira contundente a utilização da tecnologia no processo de entendimento e constituição de repertório geográfico. Diante dos mapas, cartas geográficas e estelares, bússolas, sextantes, constituídos e construídos pelo impulso de conquista e conhecimento, trilhou-se não só o caminho das grandes (e reais) descobertas marítimas, mas construiu-se uma forma de relacionamento e de percepção de um mundo cada vez mais domesticado e milimetricamente escaneado.

Um dos dramas do mundo contemporâneo é que a Terra foi
"desnaturada", e o homem só pode vê-la através de suas medidas
e de seus cálculos, em lugar de deixar-se decifrar sua escrita sóbria
e vivida. Nossa civilização e uma ciência muitas vezes abandonada
à vulgaridade multiplicaram os números de seres privados de todo
o vigor provincial, da sabedoria prudente e enérgica que provém
do contato cotidiano com a planície, a vertente ou o vagalhão,
do ritmo natural da vida no meio das coisas. (Dardel, 20I I, p. 96)

Mapas, bússolas, GPS, dispositivos eletrônicos e outros elementos técnicos, em Manual de localização imaginária, são utilizados como referência à vida contemporânea "desnaturada" ou "domesticada", e assim são propositadamente reapresentados com a intenção de modificar sua trajetória na paisagem cultural e histórica. Nesse aspecto, os trabalhos procuram perverter o uso utilitário desses aparatos técnicos destituindo-lhes sua funcionalidade original e provocando novas possibilidades no encadeamento entre formas, signos, imagens (Bourriaud, 2009).

Partindo desse pressuposto, o processo de trabalho determina que todo o aparato pode ser manipulado para oferecer possibilidades de uma abordagem estética, onde a verdade não se relaciona a uma situação factual, mas a uma situação conectada a imaginação.

A primeira produção, dentro de Manual de localização imaginária, foi o trabalho intitulado Ponto XIMapa | Mapa/Ponto 0, um díptico, produzido em 2009, com a utilização de fotografia digital (figura I). 
O corte, a edição, os apagamentos e o desfoque que estão presentes no trabalho sugerem que algo precisa ser completado pelo observador. As imagens determinam uma situação onde o Manual não realiza um pacto com a realidade, mas provoca um deslocamento desta e problematiza as relações visuais e conceituais sobre localização espacial e elementos técnicos, os quais utilizamos para levar a termo nosso sentido de percurso e deslocamento.

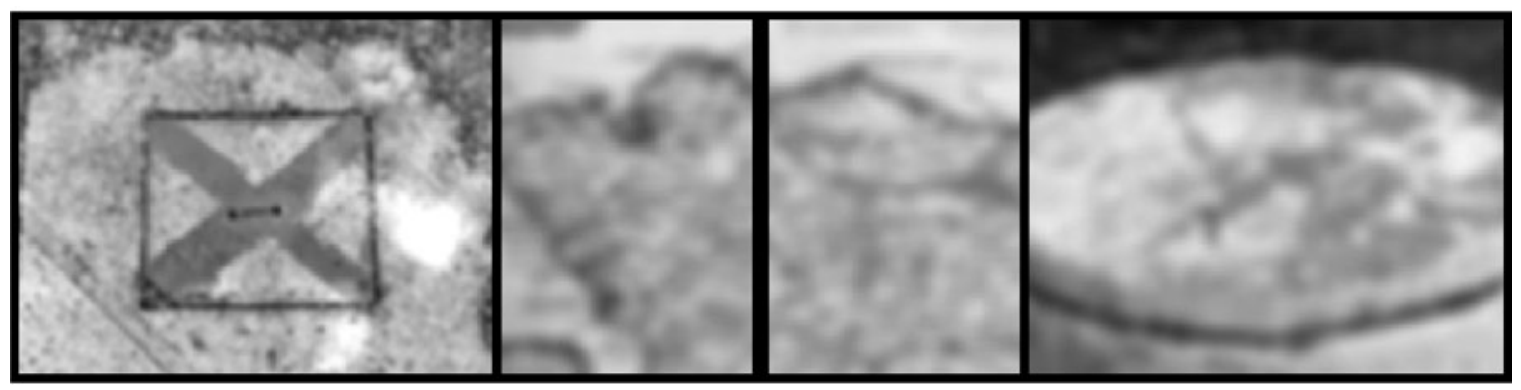

Figura I. Ponto XIMapa | Mapa/Ponto 0, da série Manual de localização imaginária, 2009. Díptico (montado de modo a unir as duas partes na intersecção do mapa). Dimensões: $45 \times 180$ $\times 5 \mathrm{~cm}$ (tamanho total). Técnica e materiais utilizados: fotografia digital impressa sobre PVC expandido, montagem em caixa de madeira laqueada preta.

○ue se pretende é provocar um embate entre a utilização desses meios e nossa própria relação com os processos de orientação espacial.

As fotografias utilizadas são indicações de marcações de locais (marco X, um mapa, ponto 0): elas são propositadamente desfocadas e quando vistas de perto são ininteligíveis; para se perceber completamente as imagens é preciso visualizá-las a certa distância. Elimina-se aí uma função do "mapa" e pontos de orientação - que é de aproximar, informar, orientar - e acrescenta-se outra noção que provoca o afastamento e a desorientação pelo desfoque, na qual o conjunto só é compreensível quando visto em panorâmica, o que força a observação do trabalho à distância para que as imagens se formem em sua completude.

Nesse sentido, a conversão de significados funcionais em significados poéticoconceituais também está presente na apresentação do trabalho, pois a montagem propõe ruídos visuais estabelecidos pelos caixilhos pretos da caixa-moldura, em uma referência formal às dobras dos mapas que se carregavam em viagens.

Outra produção dentro de Manual de localização imaginária é intitulada Lugares imaginários, e trata da constituição de uma seqüência de imagens baseada em lugares fictícios tendo como referência o livro Dicionário de lugares imaginários, de Alberto Manguel e Gianni Guadalupi (2003). 
A realização material desse trabalho está fundamentada na utilização de impressões gráficas, fotografias e manipulação digital de imagens, que são finalizadas em transferências sobre chapas de PVC. Novamente, a finalização da montagem ressalta a qualificação de cada módulo como sendo um “documento fictício", a partir do uso de molduras e passepartouts, nos quais as imagens são expostas em uma instalação de parede (figura 2), que apresenta materiais tradicionalmente associados aos de exposições de documentos cartográficos ou arquivísticos.

A utilização de processos gráficos baseia-se na ligação histórica que esses meios estabelecem com os documentos geográficos, como por exemplo, as diversas técnicas de gravura, amplamente utilizadas na publicação de documentos geográficos, que a caracterizaram como um elemento estratégico e fundamental na disseminação das informações cartográficas no correr dos séculos.

As imagens que compõem o primeiro conjunto de Lugares imaginários (figura 3) são representações visuais da entrada de Erewhon - terra fictícia do livro homônimo de Samuel Butler, publicado em 1872. Erewhon parte de um anagrama proposto por Butler a partir da palavra nowhere (lugar nenhum). $O$ acesso a esta terra é descrito no Dicionário de lugares imaginários como "feito pela garganta de um rio que desce de montanhas muito frias" (Manguel; Guadalupi, 2003, p. I43). E a elaboração do trabalho parte, assim, de uma pesquisa iconográfica que faz referência a diversas versões para

Figura 2.Vista da instalação Lugares Imaginários 1, 2011. Transfer sobre chapa de PVC rígido, montagem em passepartout Crescent e molduras em madeira branca. Cada imagem: $18 \times 24 \mathrm{~cm}$; tamanho de cada módulo: $35 \times 45$ cm. Exposição Manual de Localização Imaginária, Galeria Vertente, Campinas, SP. a tal "entrada" descrita no livro.

Inicialmente, dezoito imagens foram capturadas na internet e tratadas em halftone, utilizando o alto contraste, para eliminar vestígios significativos do referencial. As imagens foram escolhidas pelas suas características visuais, que se aproximam do que poderíamos determinar como sendo "cartões postais": apresentam certos traços de paisagens inóspitas, reforçadas posteriormente na manipulação digital.

A seqüência de tratamento das imagens incorpora um processo gráfico, que converte o arquivo digital em uma impressão a laser sobre papel, que é transferida manualmente para uma chapa de PVC rígida. A técnica utiliza a resina acrílica como agente ativo de decalque da imagem sobre o suporte, que deve ser uma chapa rígida e higroscópica, permitindo que a imagem resinada fique impregnada sobre o PVC sem que ocorra instabilidade dimensional.

Esse movimento de transposição pode ser controlado, para promover um decalque preciso ou certo apagamento

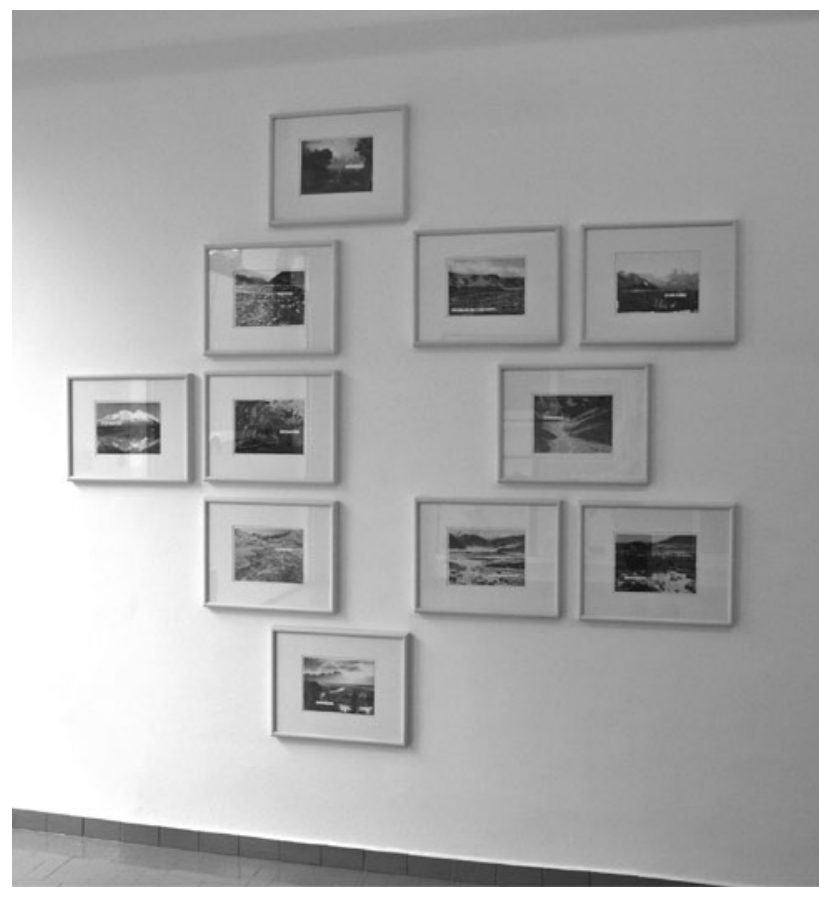


da imagem. No entanto, no processo de trabalho desenvolvido há uma preferência pela incorporação de acasos e erros que geram falhas na imagem original.

Essas falhas ressaltam uma espécie de processo de "tradução" pelo qual passa a imagem. Na cadência dos procedimentos, que se inicia com a fotografia "os dados do real são contaminados por uma infinidade de variações possíveis devido ao tratamento digital que os joga para o lado da ficção” (Rey, 2010, p. II8).
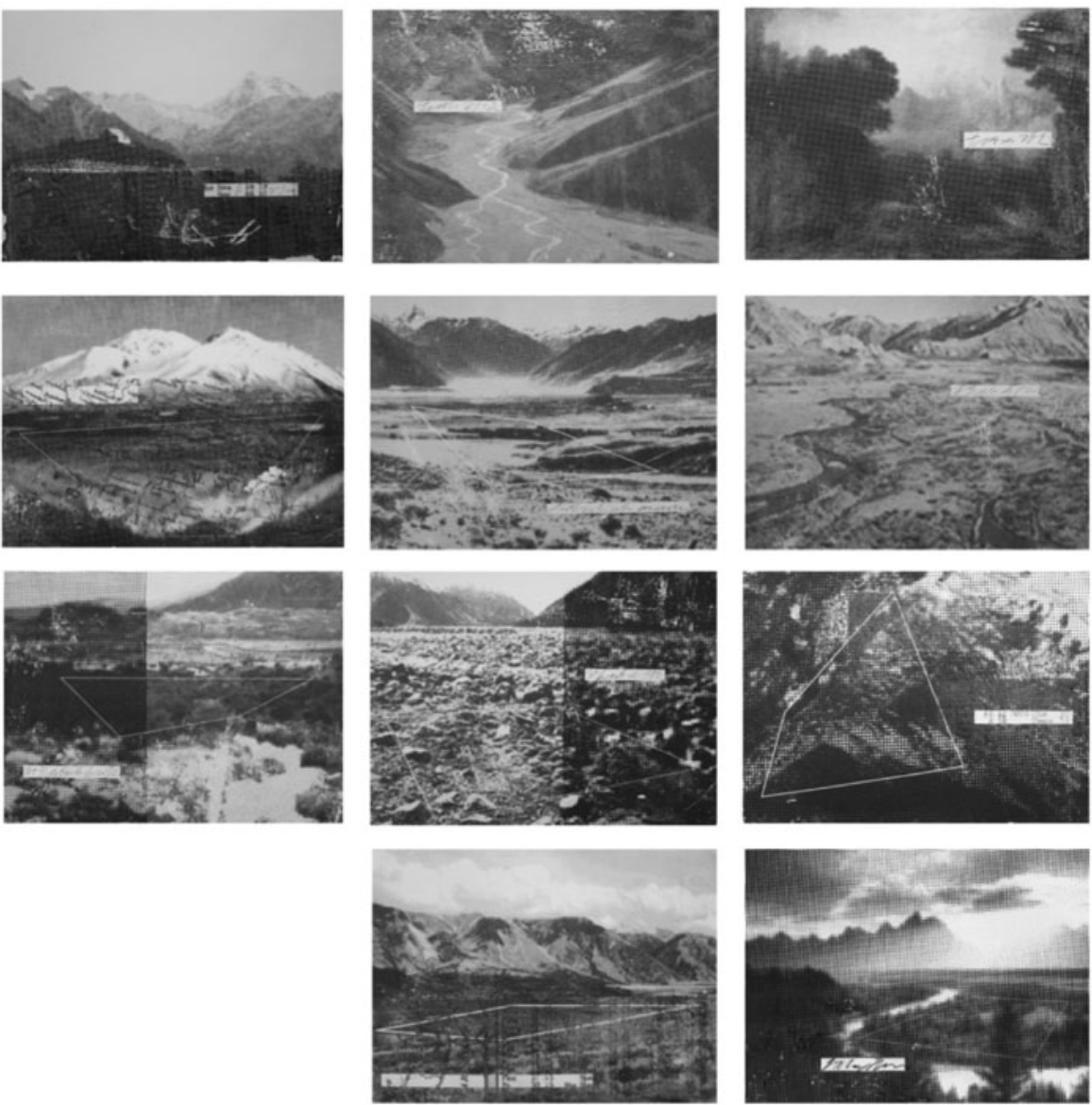

Figura 3. Lugares Imaginários I, 201 I, I $8 \times 24,5 \mathrm{~cm}$ (cada imagem). Primeiro conjunto que contém II imagens realizadas a partir de transferências de imagens impressas em laser e preparadas com resina acrílica decalcadas sobre chapa de PVC rígido.

Como desdobramento instalativo do trabalho anterior, o segundo conjunto de Lugares imaginários, contextualiza-se como uma espécie de work in progress, no qual novos elementos são incorporados a cada exposição. 
Explora a premissa de um fluxo cambiante de elementos, que cria citações visuais a partir da forma como a cidade de Ercília (Calvino, 1990) é descrita no Dicionário de lugares imaginários (Manguel; Guadalupi, 2003, p. I42-143).

Cidade de localização cambiante onde, para estabelecer relações as ligações que orientam a vida da cidade, os habitantes estendem fios entre as arestas das casas, brancos ou pretos ou cinza ou pretos-e-brancos, de acordo com as relações de parentesco, troca, autoridade, representações. Quando os fios são tantos que não se pode mais atravessar, os habitantes vão embora: as casas são desmontadas; restam apenas os fios e os sustentáculos dos fios.

Os habitantes reconstroem Ercília em outro lugar.Tecem com os fios uma figura semelhante, mas gostariam que fosse mais complicada a ao mesmo tempo mais regular que a outra. Depois a abandonam e transferem-se com as casas para ainda mais longe.

Desse modo, viajando no território de Ercília depara-se com as ruínas de cidades abandonadas, sem as muralhas que não duram, sem os ossos dos mortos que rolam com o vento: teias de aranha de relações intrincadas à procura de uma forma.

Figura 4. Detalhe de Lugares Imaginários 2, 20I I. Transfer sobre chapa de PVC rígido, montagem das placas diretamente sobre a parede. Cada imagem: $18 \times 24 \mathrm{~cm}$. Trabalho apresentado na exposição Paisagem-percurso, Galeria Gravura Brasileira, São Paulo, junho a agosto de 2011 .
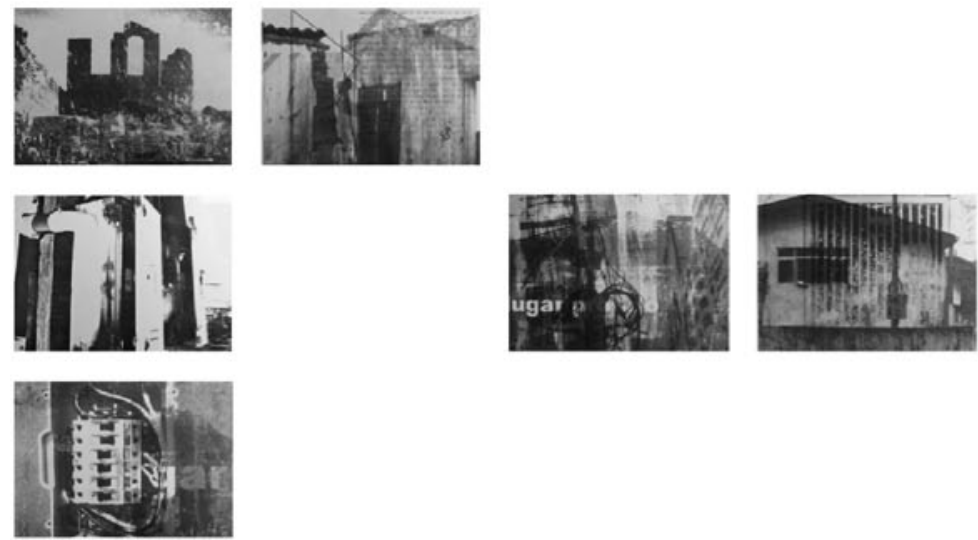
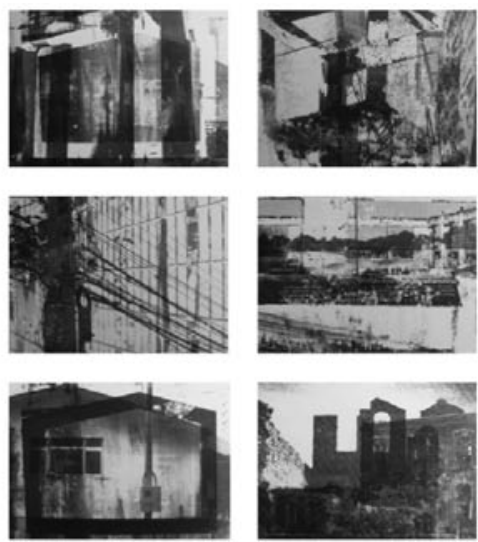
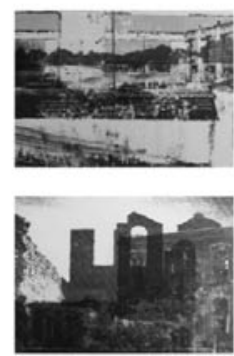
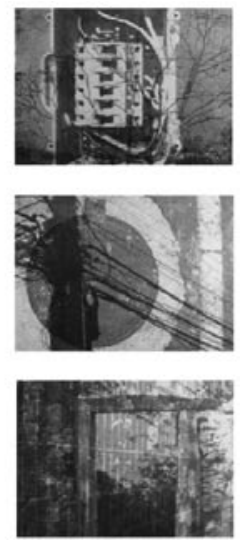
Figura 5. Cartografia ilusória I, $201 \mathrm{l}$. $25,5 \times 45,5 \mathrm{~cm}$.

Impressões de imagens digitais sobre papel Canson de $200 \mathrm{~g} / \mathrm{m}^{2} \mathrm{e}$ papel vegetal, colagem, utilização de carimbos numéricos. Montagem em pasta arquivo de poliestireno preto.
A instalação utiliza a fotografia em transferências sobre chapas de PVC (figura 4), em mini backlights e em projetores de slides e vídeo, determinando também uma espécie de história entre as "gerações" de dispositivos utilizados. A estrutura básica conceitual do trabalho é ressaltar o aspecto de espaço mutante, determinado pela forma como os habitantes de Ercília constroem sua cidade e suas relações.

Nesse contexto, novos dispositivos, imagens e cabos de força são acrescentados a cada exposição, procurando desenvolver uma espécie de mapa tridimensional, onde o acúmulo impossibilita a percepção dos pontos de ligação entre os aparelhos e as fontes de energia. A visualidade da obra faz, nesse caso, referência aos fios que os habitantes de Ercília estendem entre "as arestas das casas" (Manguel; Guadalupi, 2003, p. | 42-143) para destacar as relações de hierarquia, de afetividade etc. entre si.

Essa experiência de permanente construção e reconstrução foi também determinante para a constituição de outra série de trabalhos denominada Cartografia ilusória, que desta vez estabelece o fluxo de elaboração do processo, não mais a partir do espaço expositivo, mas sim, do espaço do ateliê.

A constituição dos trabalhos de Cartografia ilusória depende de fragmentos e materiais descartados e recolhidos durante os processos de realização de outras obras; esses fragmentos posteriormente passam por um processo de colagem, justaposição ou fixação entre si, ou sobre suportes planográficos diversos, para estabelecerem uma visualidade pseudo-documental, cuja aparência remete a um diário de viagem com referências visuais a mapas, cartões postais ou simulações de documentações e estudos topográficos etc.

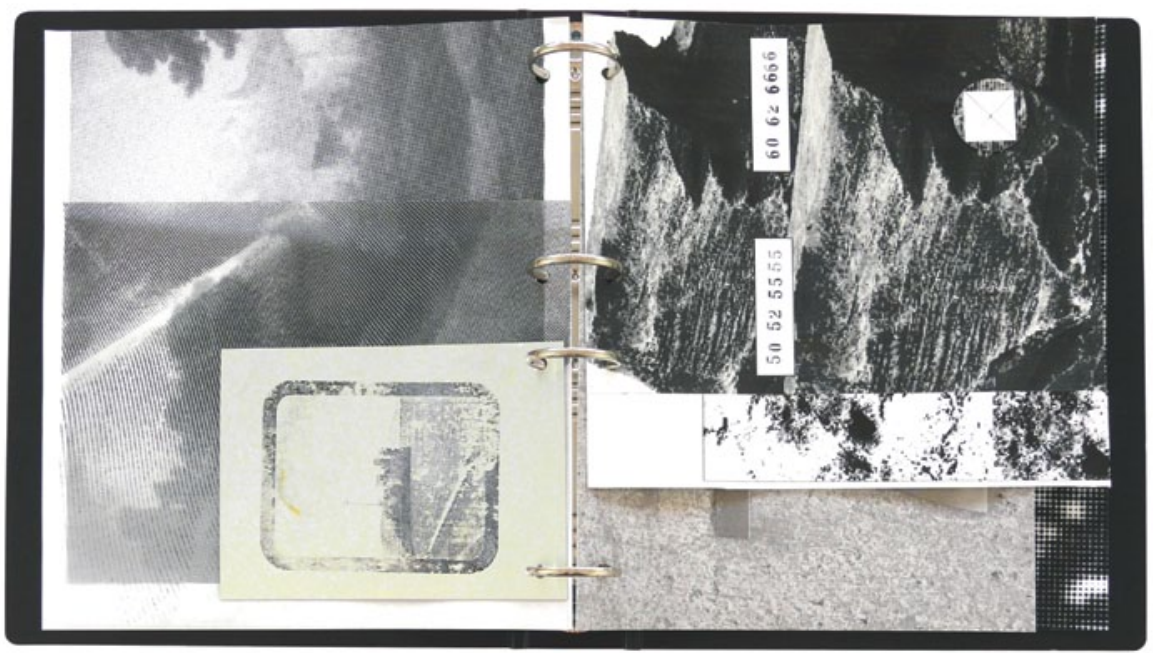


Assim, os "mapas" de Cartografia ilusória (figuras 5 e 6) são produções e experiências de ateliê que determinam que a materialidade do trabalho final seja estabelecida pelos resquícios de outros trabalhos; não se trata, portanto, como afirma Bourriaud (2009. p. 16) de "um 'produto acabado' pronto para ser contemplado, mas como um local de manobra, um portal, um gerador de atividades. Bricolam-se produtos, navega-se em redes de signos, inserem-se suas formas em linhas existentes".

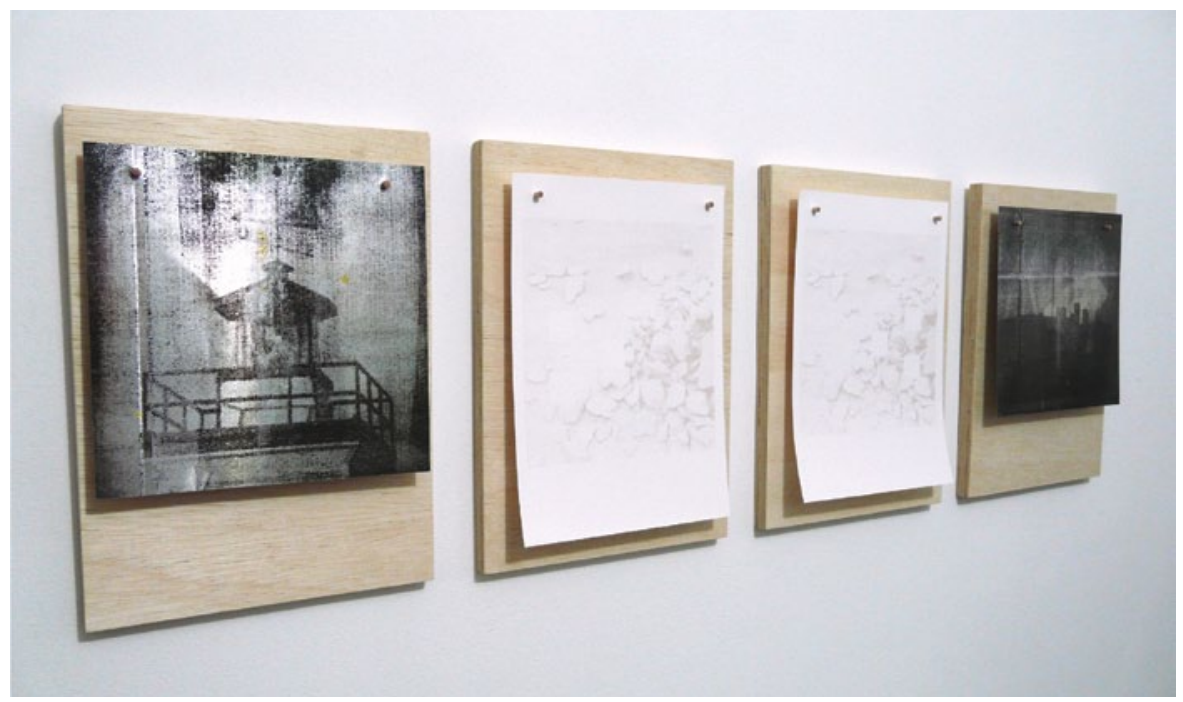

Figura 6. Cartografia ilusória 2, 2011 I. $35 \times 25$ cm (cada módulo). Impressão jato de tinta sobre papel Canson $300 \mathrm{~g} / \mathrm{m}^{2}$, impressão CTP/foto-transferência sobre chapa de alumínio de 0,20mm, recorte e fixação sobre estrutura de compensado naval de $18 \mathrm{~mm}$. Foi considerada nesta montagem a instabilidade dimensional do papel (ao centro), que se movimenta criando um contraponto a estabilidade das chapas de alumínio das laterais.

Finalizando o contexto de análise das produções realizadas em Manual de localização imaginária, o vídeo Projeções aleatórias/ imagens encontradas, é um projeto em curso, idealizado a partir de captação de imagens geradas por antigos aparelhos de projeção, como por exemplo, projetores de slides e moviolas para filmes super-8.

As questões presentes nas expressões "projeções aleatórias" e "imagens encontradas" remetem ao próprio processo de constituição do trabalho, que depende de imagens encontradas ao acaso em aparelhos antigos, comprados ou também encontrados, que representam os resquícios de um tempo perdido e estagnado.

A opção por esses aparelhos faz referência à obsolescência de certas tecnologias, e chama a atenção para os modos peculiares de suas projeções e constituições formais, como objetos de interesse estético, que nesse sentido atuam em uma 
prática contemporânea, que coloca a obra de arte em uma rede de significações (Bourriaud, 2009).

Os aparelhos descartados, abandonados e colocados à disposição em sebos e depósitos, são vistos nesse projeto como caixas de tempo que podem armazenar informações - quase em sentido arqueológico, pois estabelecem camadas de tempo e história, que são desveladas a cada nova investida por imagens que façam referência a paisagem.

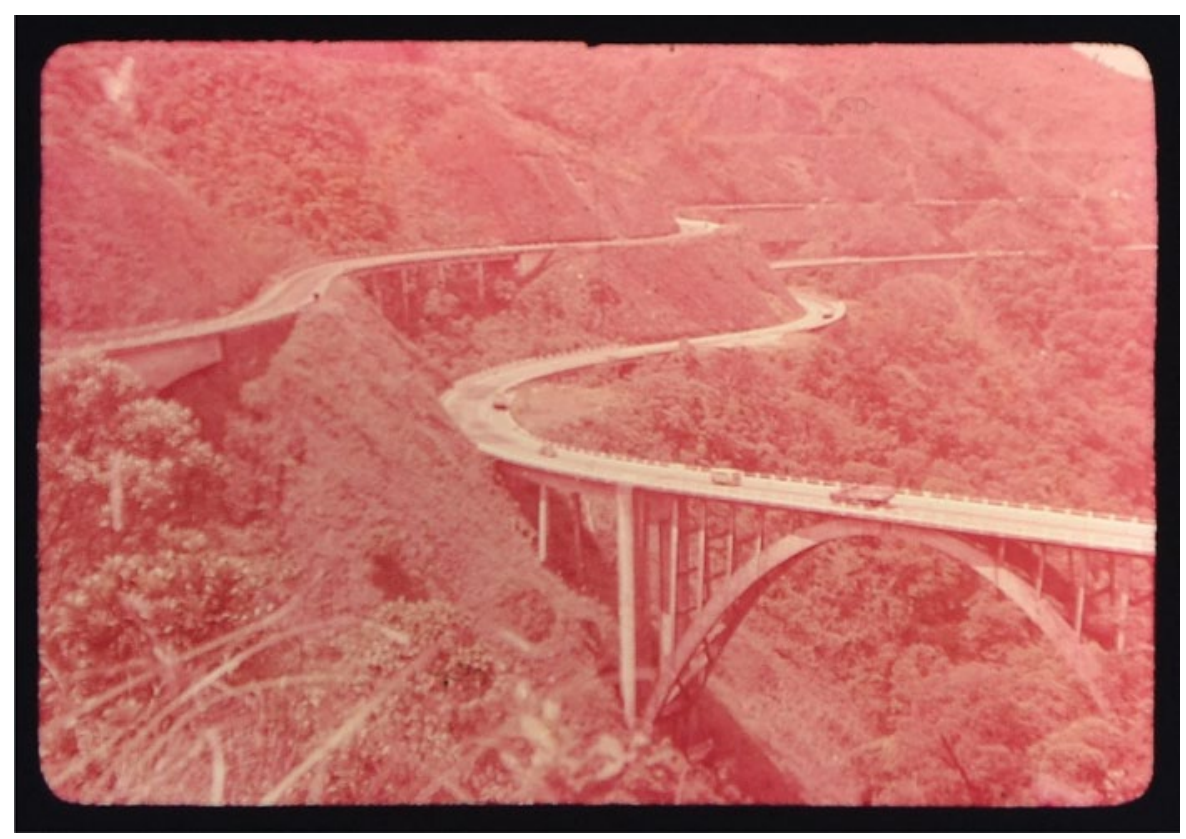

Figura 7. Imagem de slide, sem data (c. 1970), 35 mm, cor. Exemplo de slide encontrado em um dos aparelhos de projeção e utilizado no vídeo Projeções aleatórias/ imagens encontradas. Informações escritas na máscara do slide: "56/6 - Via Anchieta, Trechos da descida da Serra do Mar, Olympia color slides".

Muitos desses antigos dispositivos são descartados ainda com slides (figura 7) e filmes intactos em seu interior. $O$ próprio sentido deste trabalho converteu-se na procura por imagens de paisagens urbanas, paisagens naturais, fotografias de locais e imagens de situações particulares e privadas, cuja ideia original e valor sentimental se perderam no tempo e são reencontradas e reapresentadas em função de minhas próprias referências.

Dessa maneira, o vídeo constituído a partir dessas imagens estabelece uma nova história a partir de histórias alheias, é o "término provisório de uma rede de 
elementos interconectados como uma narrativa que prolonga e reinterpreta as narrativas anteriores" (Bourriaud, 2009, p. 16).

Manual de localização imaginária propositalmente estabelece uma seqüência de produções experimentais que estão sujeitas a alterações, correções e acréscimos no decorrer de sua construção e instauração. A maior parte dos trabalhos se configura como obras em processo, ou work in progress, relacionados ao encadeamento de conexões sígnicas entre técnica, história, memória dos objetos para a constituírem uma visualidade subjetivada e fragmentada da paisagem e de seu vínculo com um deslocamento real ou imaginário.

A paisagem nesse contexto é vista como um elemento referencial a partir do qual são evocadas as relações entre as coisas vistas e os fragmentos significativos que integram a construção poética. Pelas qualidades afetivas preservadas nesses fragmentos é possível criar uma rede de relações que colaboram para uma nova representação do espaço. Nesse aspecto, a construção poética firma-se como uma estrutura dialógica na qual a materialidade própria dos trabalhas deixa aparente ou evidencia o processo na instauração da obra.

\section{REFERÊNCIAS}

ALIATA, Fernando. A paisagem como cifra de harmonia: relações entre cultura e natureza através do olhar paisagístico. Curitiba: Editora UFPR, 2008.

BACHELARD, Gaston. $O$ ar e os sonhos. São Paulo: Martins Fontes, 1988.

BOURRIAUD, Nicolas. Pós-produção: como a arte reprograma o mundo contemporâneo. São Paulo: Martins Fontes, 2009.

CALVINO, Ítalo. As cidades invisiveis. São Paulo: Companhia das Letras, 1990.

DARDEL, Eric. $O$ homem e a terra: natureza e realidade geográfica. São Paulo: Perspectiva, 20I I.

MANGUEL, Alberto; GUADALUPI, Gianni. Dicionário de lugares imaginários. São Paulo: Companhia das Letras, 2003.

REY, Sandra. Caminhar: experiência estética, desdobramento virtual. Porto Arte, Porto Alegre, v. 17, n: 29, p. 107-12I, nov. 2010.

「]

\section{PAULA ALMOZARA}

Artista visual, pesquisadora e professora da Faculdade de Artes Visuais da Pontificia Universidade Católica de Campinas. Doutora em Educação (2005), na área de Educação, Conhecimento, Linguagem e Arte, e Mestre em Artes Visuais (1997) pela Universidade Estadual de Campinas. Atua na área de Artes em Poéticas Visuais Contemporâneas, com exposições individuais e coletivas no Brasil e no exterior. Desenvolve projetos artísticos e acadêmicos enfatizando os procedimentos gráficos, a fotografia, 0 vídeo e instalações. Site: www.paulaalmozara.art.br 
